\title{
IMPRESSION CYTOLOGY OF THE CONJUNCTIVAL EPITHELIUM IN PATIENTS WITH VERNAL CONJUNCTIVITIS
}

\author{
P. ARAGONA ${ }^{1}$, G. F. ROMEO ${ }^{1}$, D. PUZZOLO ${ }^{2}$, A. MICALI ${ }^{2}$ and G. FERRERI \\ Messina, Italy
}

\begin{abstract}
SUMMARY
The alterations in the conjunctival epithelium during the course of vernal conjunctivitis were examined by conjunctival impression cytology. The study was carried out on 53 patients with vernal conjunctivitis and 20 normal subjects as control. The results of impression cytology demonstrated that all cytological parameters were significantly modified in vernal conjunctivitis patients; the earliest alterations were found in the distribution of goblet cells, in the intercellular junctions, in the chromatin morphology and in the degree of keratinisation. The morphometric comparison showed that in vernal conjunctivitis patients the mean number of goblet cells per field was significantly higher than in controls. Moreover the mean diameter of goblet cells was smaller in patients than in controls. Impression cytology can, therefore, be a simple, non-invasive and cheap method for the study of the ocular surface in vernal conjunctivitis.
\end{abstract}

Vernal conjunctivitis is a disorder which develops early in life and is characterised by a chronic evolution, with seasonal exacerbations and remissions; it predominates in young males. There are two main clinical forms: tarsal and limbal. The former is characterised by the presence of giant papillae of cobblestone appearance in the upper tarsal conjunctiva, with mucus hypersecretion, swollen lid with ptosis, conjunctival infiltration and oedema of the lower tarsal and fornix conjunctiva which obscures most of the normal vascular pattern. The limbal form is characterised mainly by the presence, at the upper limbus, of vegetations, infiltrated by inflammatory cells, with a swollen, greyish appearance. These vegetations are often associated with various degrees of corneal pathology (from fine punctate epithelial

From: ${ }^{1}$ Institute of Ophthalmology and ${ }^{2}$ Department of Biomorphology, University of Messina, Italy.

Correspondence to: Dr Pasquale Aragona, MD, viale Boccetta, 70, I-98122 Messina, Italy. keratopathy to corneal ulcers with neovascular infiltration). In this form there is often an absence of marked tarsal papillae and mucus hypersecretion is infrequent.

The clinical evolution of the disease is routinely studied by slit lamp examination either with or without vital stains such as fluorescein and Rose Bengal which allow better assessment of the epithelial conditions. These methods of examination give only indirect knowledge about the modifications occurring in the epithelium but, on the other hand, histological sections, which might give better information, can cause discomfort to patients.

A good compromise between clinical and histological investigations is impression cytology obtained by the apposition of cellulose acetate filters on the conjunctiva. This method allows good samples of conjunctival epithelium to be obtained, is easy and cheap to perforn and, being atraumatic, is well tolerated by the patients. ${ }^{1-7}$

The aim of this investigation was to study the cytological conjunctival modifications in vernal conjunctivitis patients and to compare cytological specimens from patients with specimens obtained from healthy volunteers.

\section{MATERIALS AND METHODS}

Patient Population

Fifty-three patients (39 male and 14 female), giving a total of 106 eyes, were studied; their age was between 5 and 32 years. Patients had been symptomatic for 14-32 days when they were included in the study. In none of these patients were there extraocular symptoms.

The control group consisted of 20 healthy volunteers (40 eyes). There were 12 males and 8 females, aged between 17 and 35 years. None of these subjects had ocular or systemic diseases or was taking any drugs.

Eye (1996) 10, 82-85 c 1996 Royal College of Ophthalmologists 


\section{Specimen Collection}

Four impression cytology specimens were collected, from both eyes, at the 12 o'clock position, $2 \mathrm{~mm}$ from the limbus, in both patients and controls. Informed consent was obtained from all subjects included in the study. Specimens were fixed in a solution of glacial acetic acid, $40 \%$ formaldehyde, absolute ethanol and distilled water in the proportions 1:1:14:6 respectively, then processed for the PASPapanicolaou stain according to Gill et al. ${ }^{8}$

\section{Impression Cytology Evaluation}

The following parameters were evaluated: (1) specimen cellularity, (2) cell-to-cell connections, (3) nucleus/cytoplasm ratio, (4) nuclear chromatin, (5) goblet cell distribution, (6) presence of keratinisation, (7) presence of inflammatory cells. Each parameter was given a score as follows: 0 , normal features; 1 , borderline features; 2 or 3, abnormal features. The scores obtained for each parameter were summed to give a total score, on the basis of which the specimens were divided into three groups: group A (score 0-3), normal features; group B (score 4-6), borderline features: group C (score >7), abnormal features. ${ }^{2,9,10}$

\section{Morphometric Analysis}

Micrographs of cytological specimens were obtained with a Zeiss Axiovert 10 microscope at a standard magnification $(\times 40)$. The pictures were acquired with a Tamron Fotofix TF 56 WG film scanner and elaborated with a Macintosh CI computer running OPTILAB (Graphtek) software. For goblet cell analysis the following parameters were tested: minimum diameter, maximum diameter, mean diameter, number of cells per field. Values were expressed in micrometres. For cell diameter measurements a Leitz micrometric slide was used (Leitz, Wetztar) as standard reference.

\section{Statistical Analysis}

Statistical analysis of the results was performed using an analysis of variance.

\section{RESULTS}

The cytological results showed the presence of alterations of the conjunctival epithelium in 31 of the 53 vernal conjunctivitis patients (62 eyes, $58.5 \%$ ). Among these, 19 (38 eyes, 35.85\%) showed borderline cytological features and were included in group B; 12 (24 eyes, $22.65 \%$ ) showed marked alterations of the epithelium and were included in group $C$ (Fig. 1).

Although in vernal conjunctivitis patients all the parameters investigated showed a significant difference from normals, the largest alterations were demonstrated for goblet cell distribution, cell-to-cell

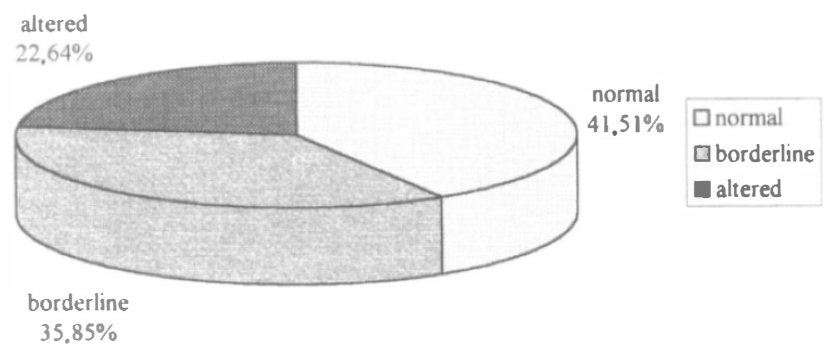

Fig. 1. Impression cytology results in vernal conjunctivitis eyes.

connections, nuclear chromatin and keratinisation (Fig. 2). Goblet cell distribution was altered in 92 eyes $(86.8 \%) ; 24$ eyes $(22.65 \%)$ showed a marked goblet cell reduction (score 2) while in 68 samples $(64.15 \%)$ goblet cells appeared to be increased in number, tending to be clumped and showing, sometimes, enhanced mucus secretion demonstrated by the presence of mucus bulks on the specimens (score 1) (Figs. 3-6). The cell-to-cell connections were altered in $54.7 \%$ of the specimens studied. A marked alteration (score 2 ) was present in 14 eyes $(13.2 \%)$, while in 44 eyes $(41.5 \%)$ there were borderline alterations (score 1) (Figs. 5-7). The nuclear chromatin was greatly altered, showing nuclear pyknosis (score 2) in 24 conjunctival samples $(22.7 \%)$; in 38 eyes $(35.84 \%)$ chromatin clumping and the presence of nucleoli were seen (score 1) (Figs. 8, 9). Keratinisation was present in 76 eyes $(71.7 \%) ; 22$ eyes $(20.7 \%)$ showed an evident squamous metaplasia with large cells with a small pyknotic nucleus (score 2 and 3); in 54 eyes (50.95\%) keratinisation was present as eosinophilia in cells with normal morphology (score 1) (Figs. 5, 9, 10).

The specimens obtained from healthy volunteers showed normal features with a total score below 3 and, therefore, were included in group A (Fig. 3). Analysis of the parameters revealed only mild alterations, with a borderline feature (score 1) of cell-to-cell relationships in 4 eyes (10\%), nucleus/ cytoplasm ratio in 2 eyes $(5 \%)$ and nuclear chromatin in 6 eyes $(15 \%)$; goblet cell distribution was abnormal in 2 eyes ( $5 \%$ ).

The morphometric analysis performed on goblet cells showed in the vernal conjunctivitis samples a mean number of $11.6 \pm 3.7$; in samples from the normal group the number of cells per field was

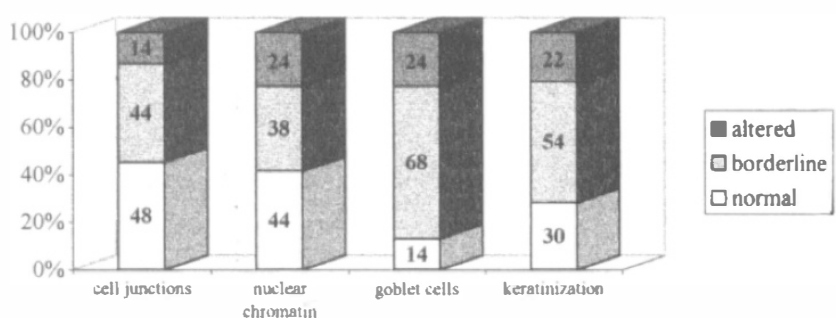

Fig. 2. Impression cytology results in vernal conjunctivitis eyes: cellular parameters. 


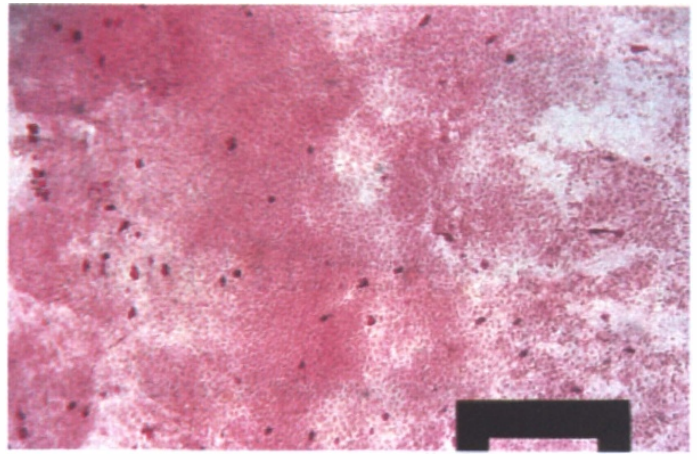

Fig. 3. Impression cytology specimen from normal conjunctiva, showing uniformly diffuse goblet cells (score 0). $P A S, \times 10$.

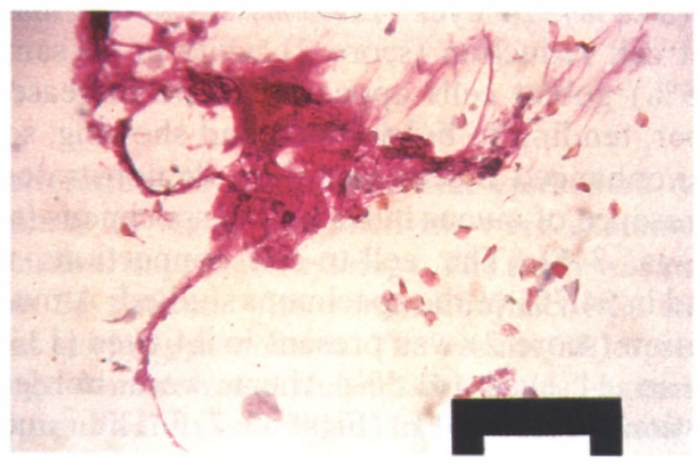

Fig. 5. Impression cytology from a vernal conjunctivitis patient, showing the presence of mucus strands and bulks (score 1), isolated cells (score 2) with a metaplasic appearance (keratinised squamous cells; score 3), a reduced nucleus/cytoplasm ratio (score 2) and pyknotic nuclei (score 2). PAS-Papanicolaou, X10.

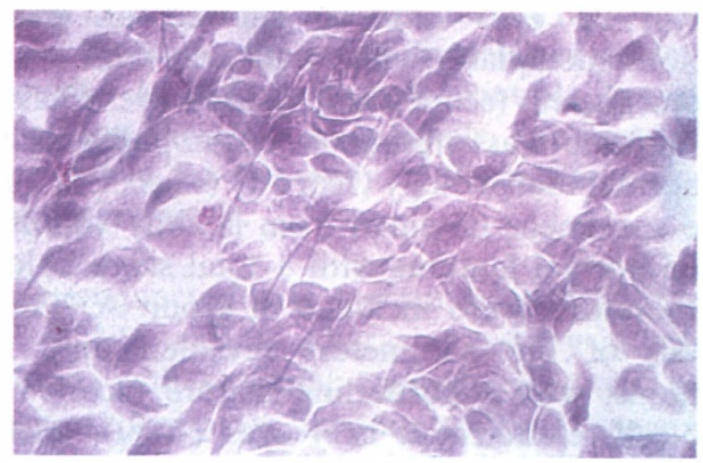

Fig. 7. Impression cytology from a vernal conjunctivitis patient showing cells with well-defined borders (score 1) in a microscopic field without goblet cells. PAS-Papanicolaou, $\times 20$.

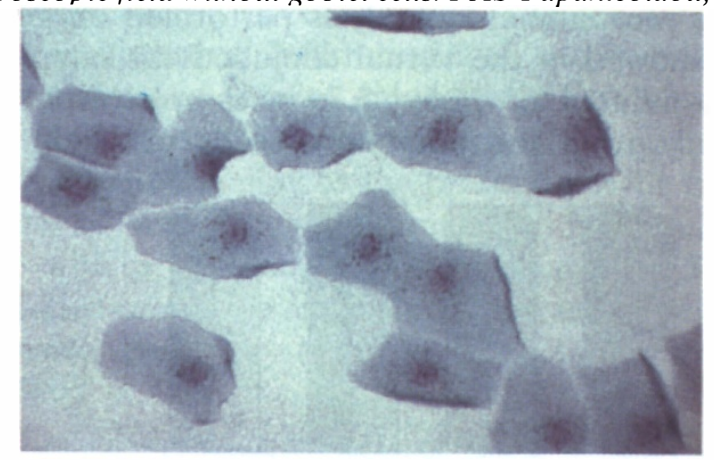

Fig. 9. Impression cytology from a vernal conjunctivitis patient showing isolated cells with markedly reduced nucleus/cytoplasm ratio (score 2) and pyknotic nuclei (score 2). PAS-Papanicolaou, $\times 40$.

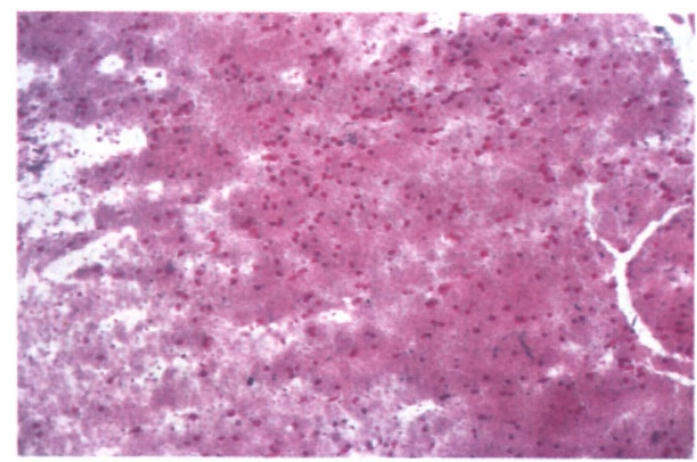

Fig. 4. Impression cytology from a vernal conjunctivitis patient, showing a large number of goblet cells tending to form clumps (score 1). PAS-Papanicolaou, $\times 10$.

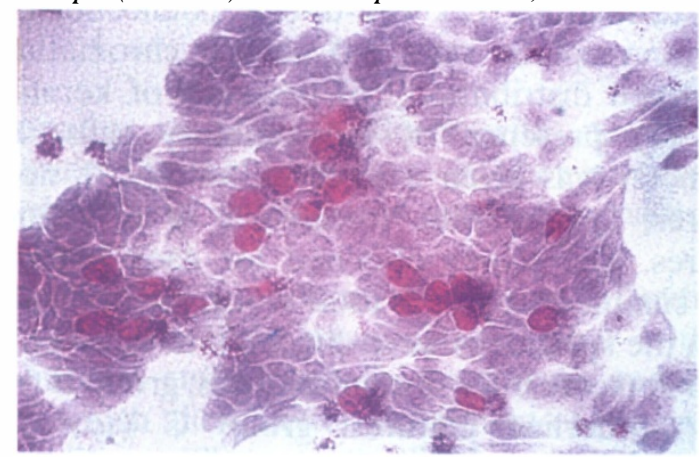

Fig. 6. Impression cytology from a vernal conjunctivitis patient showing the presence of clumped goblet cells (score 1) and cells with well-defined borders (score 1). PAS. Papanicolaou, $\times 20$.

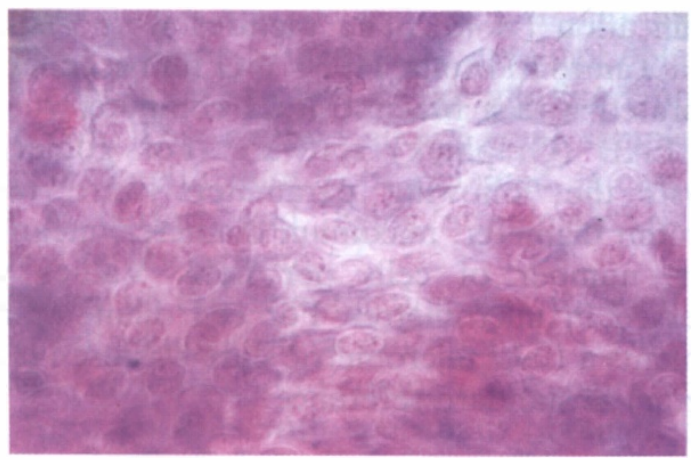

Fig. 8. Impression cytology from a vernal conjunctivitis patient showing a specimen with undefined cellular borders (score 0$)$ but with several nucleoli (score 1). PAS-Papanicolaou, $\times 30$.

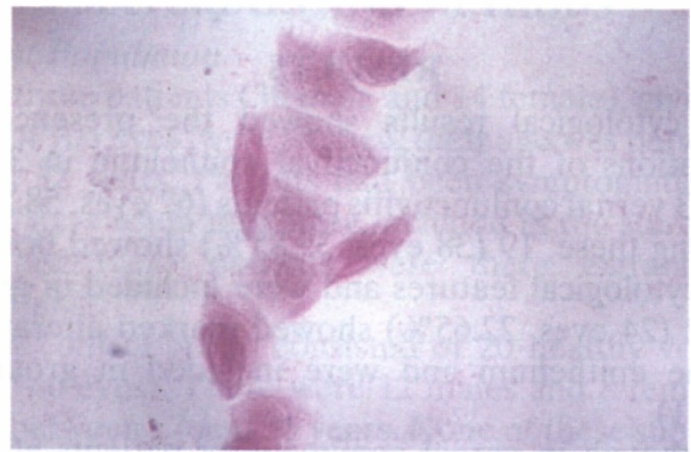

Fig. 10. Impression cytology from a vernal conjunctivitis patient showing isolated (score 2) keratinised cells (score 3) with a markedly reduced nucleus/cytoplasm ratio (score 2). PAS-Papanicolaou, $\times 40$. 
Table I. Morphometric comparison of goblet cells in cytological specimens from vernal conjunctivitis patients and controls

\begin{tabular}{lcc}
\hline & Mean & No. of \\
& diameter $(\mu \mathrm{m})$ & cells/field \\
\hline Vernal conjunctivitis patients & $12.2 \pm 3.9$ & $11.6 \pm 3.7$ \\
Controls & $16.4 \pm 3.2$ & $7.6 \pm 4.5$ \\
& $(p<0.001)$ & $(p<0.01)$ \\
\hline
\end{tabular}

$7.6 \pm 4.5(p<0.01)$. The mean diameter of goblet cells was $12.2 \pm 3.9 \mu \mathrm{m}$ in the patient group and $16.4 \pm$ $3.2 \mu \mathrm{m}$ in normal specimens $(p<0.001)$ (Table I).

\section{CONCLUSIONS}

The conjunctival epithelium of vernal conjunctivitis patients showed statistically significant alterations in all the parameters considered, but the most relevant alterations were found in goblet cell distribution, cellto-cell connections, nuclear chromatin and keratinisation. A particularly interesting feature of vernal conjunctivitis is the modification of goblet cells; in fact mucus hypersecretion is one of the main characteristics of this disease. ${ }^{11}$ Two main features of goblet cells were present in our samples: (1) an increased number of clumped goblet cells, with mucus strands on the specimen; (2) a reduced number in specimens with signs of squamous metaplasia. In our opinion the former aspect, which is more frequent, represents the first phase of the conjunctival response to inflammation; as the inflammatory stimulus continues, the conjunctiva shows a higher degree of damage that determines the latter features. The second most frequently altered parameter is keratinisation, which represents a sign of squamous metaplasia and is localised in cells with altered morphology. ${ }^{12}$ The nuclear chromatin can show the presence of several nucleoli, which are a sign of cellular activation, while in the most advanced phases of damage nuclear pyknosis appears. In normal epithelium the cell-to-cell connections are very tight and, for this reason, the cellular borders are not evident in the imprinting specimen; in vernal conjunctivitis the intercellular junctions are weaker so that it is possible to demonstrate the intercellular spaces.

The results of our study show that the conjunctival epithelium of vernal conjunctivitis patients reacts to the inflammatory stimulus with structural modifications which can be considered partly as a defence response and partly as degenerative signs. The defence phenomena are based on the increased mucus secretion, which could also play an important role in the pathogenesis of the disease, forming a scaffold on which aptens and allergens could be entrapped, maintaining the allergenic stimulus. The other modifications showed by the conjunctival epithelium during the course of vernal conjunctivitis are signs of damage to the ocular surface.

Impression cytology allows the detection of these signs and can be useful for a timely identification and follow-up of the conjunctival lesions. In this study conjunctival impression cytology showed a good maintenance of the cellular structure and the opportunity of observing the disposition of the goblet cells on the conjunctival surface. Impression cytology proved also to be a reliable method for the study of the ocular surface, with the advantage of being a cheaper and more comfortable procedure than more invasive histology. It can therefore be considered a simple and non-invasive method for the study of vernal conjunctivitis.

Key words: Cellular morphometry, Goblet cells, Impression cytology, Vernal conjunctivitis.

\section{REFERENCES}

1. Duke Elder S. System of ophthalmology, vol VIII, Diseases of the outer eye, part 1. London: Henry Kimpton, 1965:475-93.

2. Allansmith MR. The eye and immunology, part II. St Louis: CV Mosby, 1982: 118-24.

3. Buckley RJ. Vernal keratoconjunctivitis. Int Ophthalmol Clin 1988;303-8.

4. Trombetta C, Aragona P, Candela V, Scullica MG, Arena F, Tuccari G. Studio della componente mucosa della secrezione lacrimale nella congiuntivite primaverile e nella intolleranza alle lenti a contatto. Soc Oftalmol Lombarda 1986;41:163-8.

5. Nelson D, Havener VR, Cameron JD. Cellulose acetate impressions of the ocular surface. Arch Ophthalmol 1983;101:1869-72.

6. Tseng SGC. Staging of conjunctival squamous metaplasia by impression cytology. Ophthalmology 1985; 96:728-33.

7. Goetz ML, Jaeger W, Kruse FE. Die Impressiozytologie als nicht invasive Methode der Bindehaut-biopsie und ihre Ergebnisse. Klin Monatsbl Augenheilkd 1986;188:23-8.

8. Gill GW, Frost JK, Miller KA. A new formula for a half-oxidized hematoxylin solution that neither overstains nor requires differentiation. Acta Cytol 1974; 18:300-11.

9. Aragona P, Candela V, Scullica L. A new method of evaluation of conjunctival alterations with impression cytology. In: Miglior M, van Bijsterfeld P, Spinelli D, editors. The lacrimal system. Kuglers-Ghedini, 1992: $117-21$.

10. Moodley LCM, Aragona P, Garner A, Buckley RG. Conjunctival changes in contact lens wear evaluated by impression cytology. In: XVII Congress Européen de Contactologie Médicale, Grenoble, 1987.

11. Aragona P, Candela V, Scullica L. Chemical and histochemical evaluation of tear mucus variation in clinical and experimental conditions. In: Miglior M, Spinelli D, Fabbri G, editors. The lacrimal system. Kuglers-Ghedini, 1988:121-4.

12. Candela V, Castagna I, Aragona P, Villari D. I processi di cheratinizzazione dell'epitelio corneo-congiuntivale. Boll Ocul 1990;(Suppl I):161-3. 